\title{
DETERMINATION OF THE VIBRATION WITHIN A SQUEEZE-FILM DAMPER UNDER ROTATIONAL UNBALANCE CONDITIONS FROM EXTERNALLY MOUNTED SENSORS
}

DOI:

10.1115/GT2019-90017

\section{Document Version}

Accepted author manuscript

Link to publication record in Manchester Research Explorer

\section{Citation for published version (APA):}

Al-Ghazal, G., Bonello, P., \& Torres Cedillo, S. (2019). DETERMINATION OF THE VIBRATION WITHIN A SQUEEZE-FILM DAMPER UNDER ROTATIONAL UNBALANCE CONDITIONS FROM EXTERNALLY MOUNTED SENSORS. In Proceedings of ASME Turbo Expo 2019: Turbomachinery Technical Conference and Exposition GT2019 June 17-21, 2019, Phoenix, Arizona, USA https://doi.org/10.1115/GT2019-90017

\section{Published in:}

Proceedings of ASME Turbo Expo 2019: Turbomachinery Technical Conference and Exposition GT2019 June 1721, 2019, Phoenix, Arizona, USA

\section{Citing this paper}

Please note that where the full-text provided on Manchester Research Explorer is the Author Accepted Manuscript or Proof version this may differ from the final Published version. If citing, it is advised that you check and use the publisher's definitive version.

\section{General rights}

Copyright and moral rights for the publications made accessible in the Research Explorer are retained by the authors and/or other copyright owners and it is a condition of accessing publications that users recognise and abide by the legal requirements associated with these rights.

\section{Takedown policy}

If you believe that this document breaches copyright please refer to the University of Manchester's Takedown Procedures [http://man.ac.uk/04Y6Bo] or contact uml.scholarlycommunications@manchester.ac.uk providing relevant details, so we can investigate your claim.

\section{OPEN ACCESS}




\title{
DETERMINATION OF THE VIBRATION WITHIN A SQUEEZE-FILM DAMPER UNDER ROTATIONAL UNBALANCE CONDITIONS FROM EXTERNALLY MOUNTED SENSORS
}

\author{
Ghaith Ghanim Al-Ghazal \\ School of Mechanical, Aerospace and Civil \\ Engineering, University of Manchester, Manchester, \\ United Kingdom
}

\author{
Philip Bonello \\ School of Mechanical, Aerospace and Civil \\ Engineering, University of Manchester, \\ Manchester, United Kingdom
}

\author{
Sergio G. Torres Cedillo \\ Centro Tecnológico Aragón, FES Aragón, Universidad Nacional Autónoma de \\ México (UNAM), Av. Rancho Seco s/n, Edo. de México, México. C.P. 57130
}

\begin{abstract}
Recently, there has been a focus on the use of inverse problem techniques in order to monitor rotor unbalance, and obtain a balancing solution, from vibration measurements on the casing and prior knowledge of the rotor-casing structure. In certain practical configurations that use nonlinear bearings like the squeeze-film damper (SFD) bearing, an inverse model of the bearing is an important part of the unbalance identification process. The inverse bearing model is used to estimate the journal vibration from casing vibration measurements, thus acting as a substitute for internal instrumentation in applications where the rotor is not accessible under operational conditions. Previous research has shown that an inverse bearing model can be identified using a trained Recurrent Neural Network (RNN) from experimental input/output data. However, the RNN was both trained and validated under simulated rotational conditions, wherein the motion was driven by two orthogonally-phased perpendicular shakers.

In this paper, a RNN of an inverse bearing model that is identified from experimental data generated under simulated rotational conditions is validated under actual rotational (i.e. unbalance-driven) vibration conditions. The necessary modifications to the test rig are presented, together with the identification/training procedure. The results of the validation tests show that the RNN is capable of predicting the frequency spectrum of the dynamic nonlinear response of the journal with reasonable accuracy. This inverse SFD bearing model can be thus used in a future work to identify rotor unbalance.
\end{abstract}

\section{INTRODUCTION}

A cost-effective means of introducing damping into the rotordynamic system (e.g. aero-engine) is achieved by surrounding the outer race of the rolling-element bearings with a film of oil (SFD), as shown in Figure 1. Typical aero-engine assemblies have at least two nested rotors mounted within a casing through SFD bearings. As can be seen in Figure 1, the inner side of the damper is shaped by the journal, which is a ring fixed to the outer race of the rolling element bearing and is prevented from spinning, while orbiting freely within the oil-filled annular clearance in the bearing housing.

The prediction of the dynamic response from a known unbalance distribution is referred to as the forward problem [1-9]. Its solution utilizes a forward bearing model, which has been used to identify nonlinear bearings, where the displacement is the input and the bearing force is the output [10-12]. Recent developments in modelling, mean that there are now effective solutions to the forward problem, even for nonlinear SFD bearing models. However, the real unbalance distribution under operational conditions will be unknown [2] unless an inverse problem technique is applied to identify it $[3,4]$.

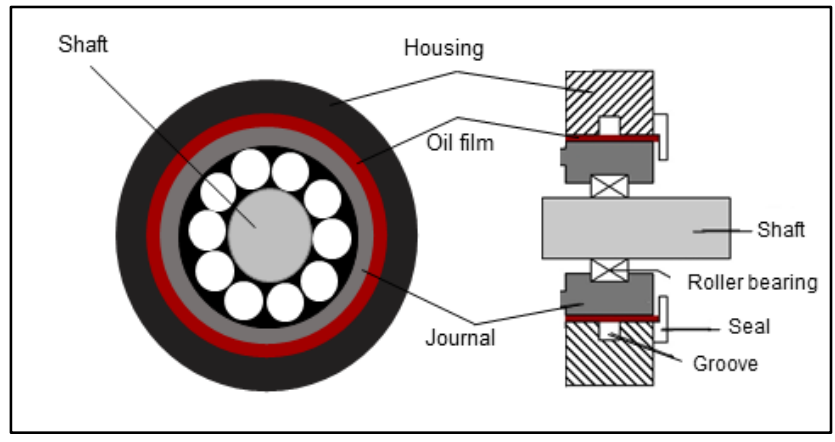

Figure 1: An SFD bearing assembly.

Recently, attention has turned to the use of inverse problem techniques in order to monitor rotor unbalance, and obtain a balancing solution, from vibration measurements on the casing and prior knowledge of the rotor-casing structure $[9,13]$. 
SFD bearings are nonlinear elements, which complicates the inverse problem that needs to be solved when identifying the rotor unbalance from vibration measurements from externally mounted sensors (on the casing/bearing housings) and a known model of the rotor/casing structure $[9,13]$. Most inverse problems for the unbalance assumed linear models of the bearings [14-17]. However, nonlinearities in the SFD should not be ignored, particularly since these become more prominent as abnormal unbalance conditions develop (i.e. when the need for balancing arises) [7]. The first work that solved an inverse problem considering nonlinearity of bearings was that by Dicken et al [3]. In [3], a rotor-casing system with one SFD was considered. The SFD model was nonlinear, but assumed circular centered orbits. A theoretically-derived database relating the bearing force with the amplitude of the vibration of the journal relative to the housing (casing) was used to solve the problem. The inverse problem of [3] was therefore implicit.

Torres Cedillo and Bonello [7] considered a more generic form of the system considered by Dicken et al [3] and showed that an effective balancing solution can be obtained by explicit inversion, without making any assumptions on the nonlinearity of the bearing, provided there is at least one linear connection between the rotor (source of the unbalance) and the casing (measurement positions), apart from the non-linear ones, as was the case in [3]. If there is one weak linear connection (e.g. when rotor and casing are connected through a single soft retainer spring, as in [8]) then the explicit inversion problem becomes badly conditioned. If there is no linear structural coupling at all between casing and rotor, the inverse problem for the unbalance becomes fully implicit and requires an inverse bearing model to provide information on the vibration of the rotor, thus serving as a virtual instrumentation.

The inverse bearing model outputs information of the vibration of the journal relative to the housing, for given input bearing forces. The latter are determined from the readings of vibration sensors mounted on the casing (bearing housing) and the modal properties of the casing. The inverse model of a given SFD identified under prescribed conditions is therefore transferable in principle to any practical system where the SFD is installed [13].

Torres Cedillo and Bonello [13] identified an inverse SFD model using a recurrent neural network (RNN). This RNN was trained to output the current journal displacement from the time history of the bearing force and the feedback of the time history of the RNN's displacement output. This identification technique is non-parametric i.e. makes no assumption about the underlying input/output relationship. Moreover, the inverse SFD model requires a dynamic network (like the RNN) to account for the time history of the forces and the displacement, since it is not possible to determine the current value of journal displacement (output) based only on the current value of the bearing force (input). This contrasts with the forward bearing model, which can be identified using "memoryless" techniques like static neural networks [12] or Chebyshev polynomials [10,11], since it is possible to determine the current value of the output (bearing force) based only on the current value of the input (journal displacement and velocity). The nonlinear inverse SFD model in [13] was identified from empirical data (force input/displacement output) gathered from a specially designed SFD non-rotating test rig, which was excited using two orthogonal shakers. The RNN inverse SFD model was then applied in [13] to the implicit inverse rotor-bearing solution of the same experimental rig for the identification of the rotor excitation force using only the vibration measurements at the bearing housing.

Recent work [9] showed that the inverse SFD bearing model trained with RNN is also essential for finding an effective balancing solution for the case when there is just one weak linear structural connection between casing and rotor, as in a practical aeroengine design [9]. The enhancement provided by the RNN inverse bearing models to the explicit inverse problem was shown to dramatically improve its conditioning. It should be noted however, that the RNNs in [9] were trained from data generated from a theoretical SFD model.

The use of experimental data for identifying the inverse model enables the RNN to capture features that are difficult to capture theoretically, like non-circularity of the bearing profile [13]. The bearing models in [9] were identified by training a RNN using a circular chirp excitation method [18], which was proven experimentally by Al-Ghazal et al. [18] to be more effective than the training method used in [13]. The method devised by Al-Ghazal et al. [18] reproduced a reliable inverse bearing model in less training time than that of [13] through an exhaustive search method introduced recently by [19] to identify an optimal RNN topology.

Although previous work on RNN inverse SFD models $[13,18]$ used experimental data for training and validation, the rotational conditions were simulated since the motion was induced by two orthogonally-phased perpendicular shakers in both training and validation. The novel contribution of this paper is to demonstrate that an RNN inverse SFD model that is experimentally trained under simulated (shaker-induced) rotational conditions according to the chirp excitation technique of [18] can be used to predict the journal motion under actual rotational (i.e. unbalance-driven) vibration conditions.

The remaining part of the paper is structured as follows. Section 2 details the conversion of the test rig to enable rotational excitation in the validation stage. Section 3 describes the RNN model identification method for the SFD bearing (note that this is still done using controlled shakerinduced motion of the journal in the $x-y$ plane). Section 4 presents and discusses the validation tests (under unbalance excitation).

\section{TEST RIG DETAILS}

Figure 2 shows a photograph of the SFD test rig with significant items labelled and Figure 3 depicts the schematic diagram. This test rig is converted into a rotating rig from a specially designed non-rotating setup, which was used in $[12,13,18]$, where the shaft was prevented from spinning by a retainer spring that supported the static load of the rotor. The modified rotating test rig is essentially similar to a non- 
rotating one, except that a new retainer spring has been added to enable rotation and to support the static load of the shaft. It is designed such that the SFD forces and relative motion across the film may be measured. This provides the training data for the RNN-based inverse SFD model.

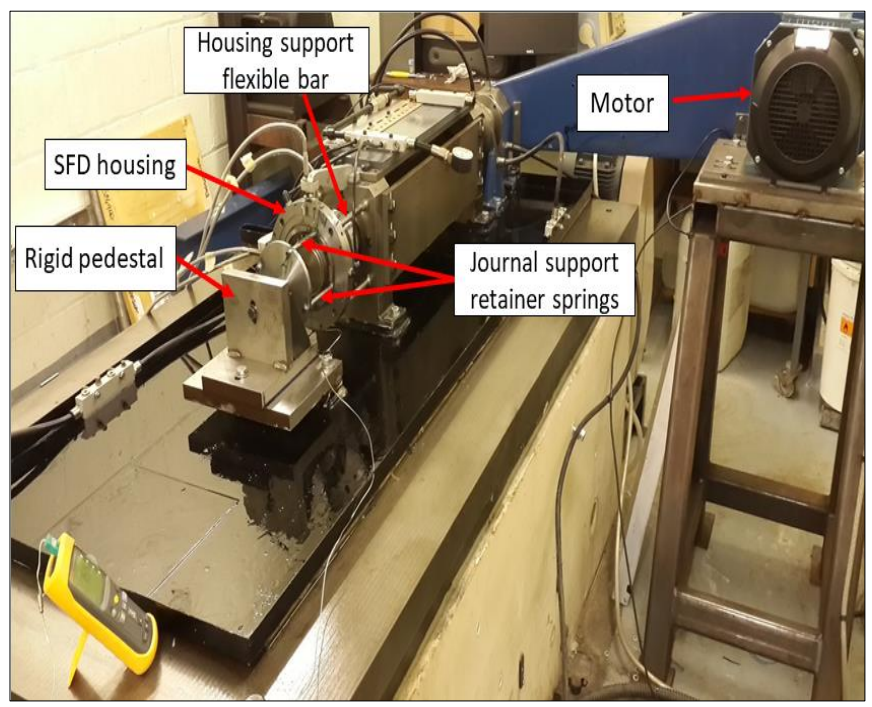

Figure 2: Photograph of the rotating test rig.

This rig configuration (Figure 3) has a single motordriven shaft, labeled (5), running in a SFD bearing at one end, $\mathrm{J}_{2}$, and in a self-aligning bearing at the other end at the other end, $J_{1}$ (4). The housing (10) of the SFD bearing is mounted flexibly through four flexible bars (6). The SFD journal (8) is spring-supported and statically offset within the housing through a purposely-designed retainer spring ((11), (12), (13)), which supports the journal on a rigid pedestal (3). The retainer spring connects the journal to the rigid pedestal rather than the housing (10) for the following reasons:
- so that the SFD (oil film) forces can be directly obtained from the vibration of the housing (10) (as per equations (2a,b) in section 3$)$;

- to allow an implicit relationship between the vibration of the housing and the unbalance on the rotor (no structural connection between them).

The oil is pumped into the annular clearance between the journal (8) and the bearing housing (10), thus forming the SFD (9) (see also Figure 4). As shown in Figure 4, the installed SFD bearing has two lands of length $6.23 \mathrm{~mm}$ each, separated by a groove of depth of $7.52 \mathrm{~mm}$ and width $2.03 \mathrm{~mm}$. The radial clearance of the SFD is $0.09 \mathrm{~mm}$ and the SFD journal radius is $69.8 \mathrm{~mm}$. The oil is provided through three equispaced feed ports in the bearing housing, each feed port diameter being $1.5 \mathrm{~mm}$ and their lengths are $25 \mathrm{~mm}$. As depicted in Figure 4, the SFD is unsealed at one face and lightly sealed at the other. As in all SFDs, the journal (8) is prevented from spinning, in this case by the retainer spring (11), but is allowed to orbit within the oil-filled clearance in the $x-y$ plane. The shaft itself can rotate due to the rolling element bearing (7).

The structure is rigidly bolted down to a cast iron bedplate (16), which is itself fixed onto a massive concrete block that rests on ground at basement level of the building. The drive shaft (5) is belt-driven using an electric motor at (1), which is bolted to the ground (motor and belt drive not shown) and the torque is transferred to the shaft at (2) via coupling.

An unbalance ring (14) is mounted over the rotor for the attachment of unbalance masses (15) that excite the system under rotational conditions. The design of the new retainer spring ((11), (12), (13)) is described in the following subsection.

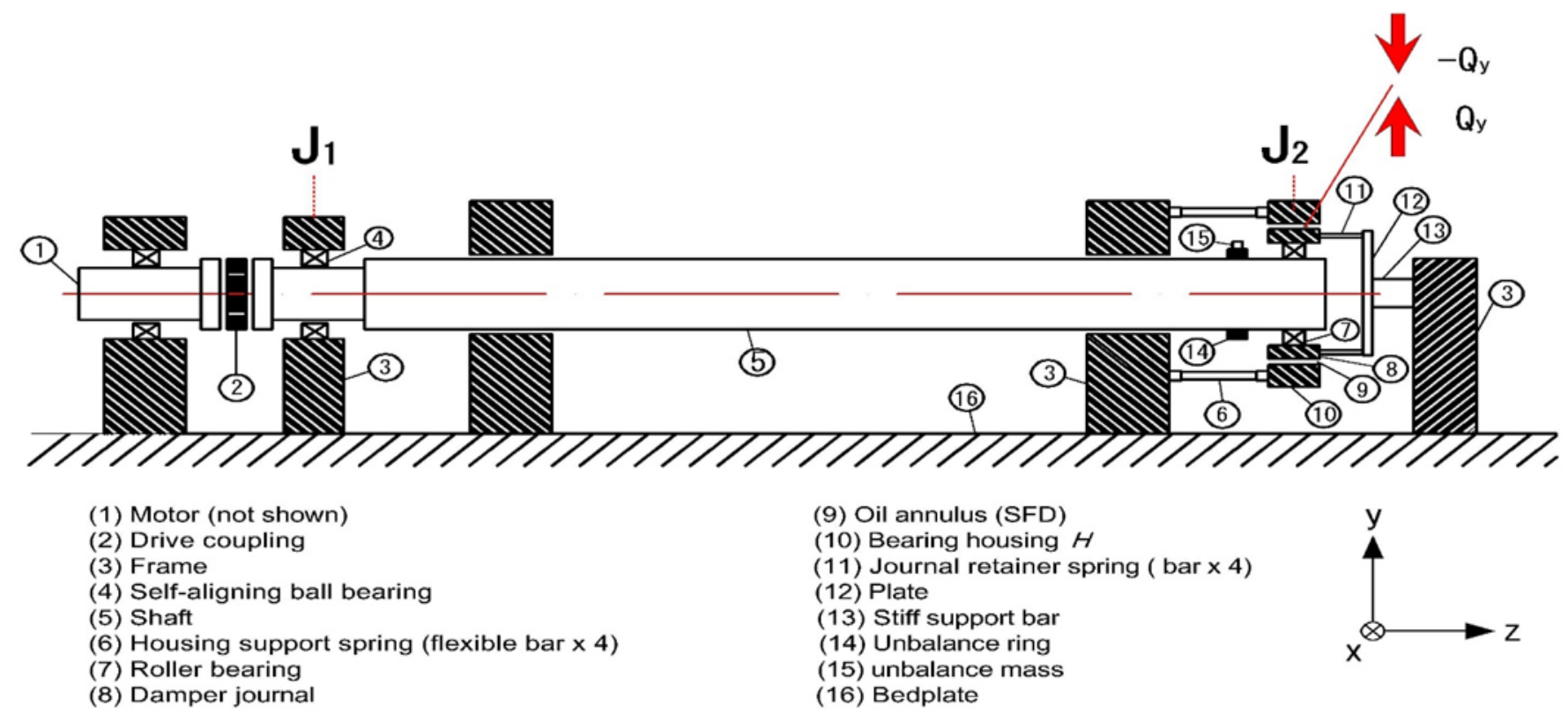

Figure 3: Test rig axial cut through (forces in $x$-direction not shown). 


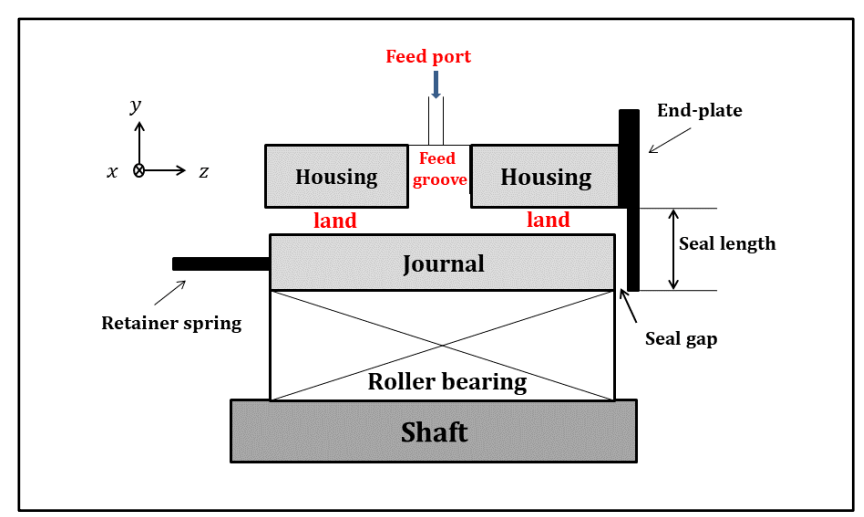

Figure 4: Cross section of the SFD.

\subsection{SFD RETAINER SPRING DESIGN}

Figure 5 shows the retainer spring that was designed and manufactured for the research of this paper, and how it fits with the flexibly mounted bearing housing (via the SFD). The retainer spring was designed to be considerably more flexible than the mounting of the bearing housing, as in practical applications. An FE analysis of the retainer spring (Figure 6) showed that its stiffness was $0.322 \mathrm{MN} / \mathrm{m}$. An FE analysis of the mounting of the housing (Figure 7) showed that its stiffness was $6.2 \mathrm{MN} / \mathrm{m}$. This latter value agrees with the experimentally determined value of the same mounting in [20]. The FE models have been created using Abaqus 6.14 [21].

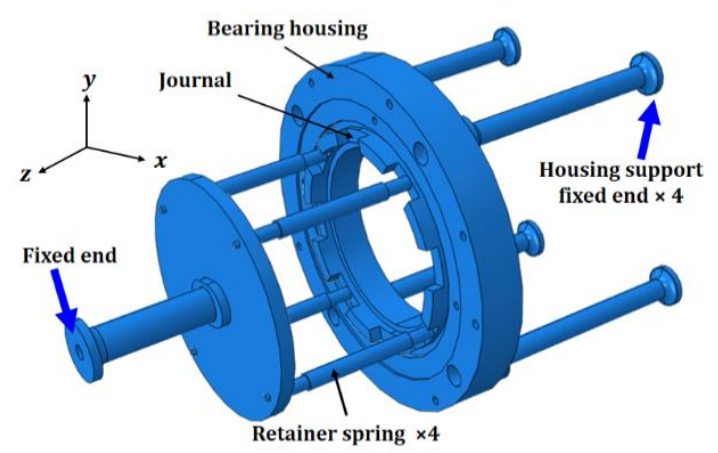

Figure 5: Assembly of retainer spring, journal and bearing housing.

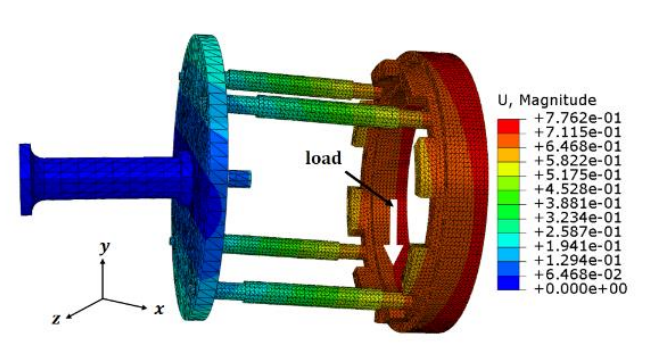

Figure 6: FE model of retainer spring under a steady load of $250 \mathrm{~N}$ applied on the journal.

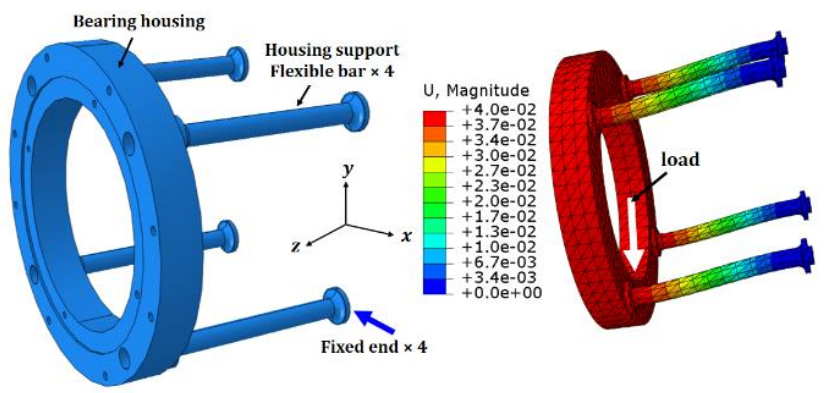

Figure 7: FE model of flexibly-mounted bearing housing under steady load of $250 \mathrm{~N}$ applied to the bearing housing.

\section{RNN CHIRP IDENTIFICATION METHOD OF AN INVERSE SFD MODEL VIA SHAKER EXCITATION RESPONSE}

For training the RNN, journal motion within the SFD annular clearance is induced by circular chirp excitation applied to the non-rotating shaft via two orthogonally-phased perpendicular shakers (Figure 8), as in $[9,13,18]$.

\subsection{TRAINING DATA DETERMINATION FROM A NON-ROTATING RIG SETUP}

Figure 8 shows the SFD end of the setup where a collar (consisting of two pieces (14)) is mounted on the rotor with orthogonal tappings to enable the connection of the rods between the rotor and the two shakers (these replaced the rotational unbalance ring (14), (15) in Figure 3 for the purpose of the non-rotational tests). As in [18], the shakers are driven by custom-generated input signals to apply the excitation forces $P_{x}, P_{y}$ (shown in Figure 8 ) to the rotor. The $P_{x}, P_{y}$ forces are made to have constant and equal amplitudes as well as perpendicular phasing, resulting in circular chirp excitation which is expressed as follows $[9,18]$ :

$$
\begin{aligned}
& P_{x}(t)=A \cos \left(2 \pi\left\{f_{\text {init }} t+\frac{\Delta f}{\Delta t}\left(\frac{t^{2}}{2}\right)\right\}\right) \\
& P_{y}(t)=-A \sin \left(2 \pi\left\{f_{\text {init }} t+\frac{\Delta f}{\Delta t}\left(\frac{t^{2}}{2}\right)\right\}\right)
\end{aligned}
$$

where

$$
\frac{\Delta f}{\Delta t}=\frac{f_{\text {end }}-f_{\text {init }}}{t_{\text {end }}-t_{\text {init }}}
$$

The constant amplitude is denoted by $A$, whilst the applied final and initial values of the time and excitation frequencies are denoted by the subscripts end and init. During testing, the oil supply pressure and temperature were maintained at $0.8 \mathrm{bar}$ and $29^{\circ} \mathrm{C}$ respectively, in line with previous works e.g. [12]. The oil used was Shell Morlina grade 5 (viscosity $0.006 \mathrm{~Pa} \cdot \mathrm{s}$, density $869 \mathrm{~kg} / \mathrm{m}^{3}$ ). 


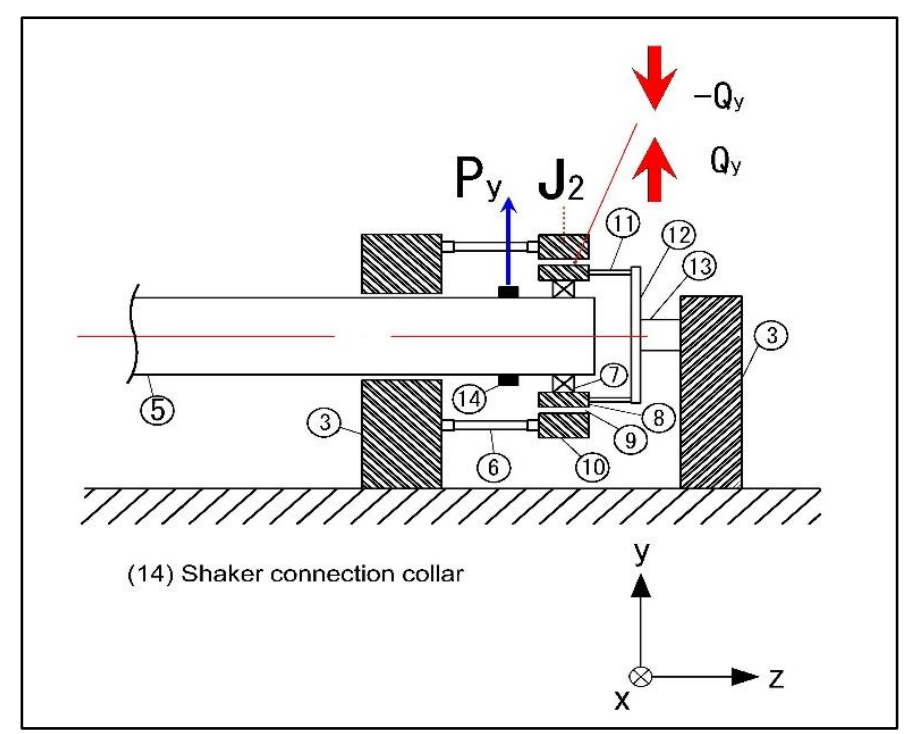

Figure 8: The SFD end of the non-rotating setup under the shaker excitation $P_{x}, P_{y}$ (forces in $x$-direction not shown).

To train a neural network, input/output training data are required, where the SFD forces are the input and the relative motion Cartesian components are the output (target). The instantaneous displacements of the journal relative to the bearing housing $\left(x_{\mathrm{r}}, y_{\mathrm{r}}\right)$ are measured by a pair of orthogonal proximity probes mounted on the bearing housing (10). The displacement and acceleration of the bearing housing are measured in order to determine the SFD forces $Q_{x}, Q_{y}$, which are computed as in $[12,13,18]$ using the known modal data of the bearing housing (10) supported by the flexible suspension (6) (i.e. the support structure subsystem, as shown in Figure 2 and 3 ).

These modal data were determined in [12]. They characterise the dynamics of the bearing housing support structure subsystem as a spring-mass model in both the $x z$ and $y z$ planes for frequencies up to $800 \mathrm{~Hz}$. Hence, the SFD forces on the bearing housing $-Q_{x},-Q_{y}$ are expressed by:

$$
\begin{aligned}
& -Q_{x}=M_{\mathrm{H} x} \ddot{x}_{\mathrm{H}}+k_{\mathrm{H} x} x_{\mathrm{H}} \\
& -Q_{y}=M_{\mathrm{H} y} \ddot{y}_{\mathrm{H}}+k_{\mathrm{H} y} y_{\mathrm{H}}
\end{aligned}
$$

where $M_{\mathrm{H} x}, M_{\mathrm{H} y}$ and $k_{\mathrm{H} x}, k_{\mathrm{H} y}$ are the effective mass and stiffness constants of the bearing housing in the $x z$ and $y z$ planes respectively [12]. The absolute Cartesian displacements of the bearing housing (10) are denoted by $x_{\mathrm{H}}, y_{\mathrm{H}}$, and are measured by proximity probes mounted on the rigid frame (3) and aimed at (10). The accelerations $\ddot{x}_{\mathrm{H}}, \ddot{y}_{\mathrm{H}}$ are measured by accelerometers mounted on the housing (10).

The training data are generated as three sets from three shaker force amplitudes of $P_{x}, P_{y}$ in eq. (1) of $20,50,80 \mathrm{~N}$, respectively for 50 seconds, at separate frequency sweeps (10100) Hz. Force gauges are used to monitor the shaker forces. Figure 9 shows the training data obtained with a shaker force amplitude of $20 \mathrm{~N}$. The amplitudes of the SFD forces in the $x$ and $y$ directions are significantly different due to the different amplitudes of the $x$ and $y$ relative displacements. This significant difference between the $x$ and $y$ directions was only observed with the lowest amplitude of shaker force $(20 \mathrm{~N})$ and did not happen with higher shaker force amplitudes $(50 \mathrm{~N}, 80$ $\mathrm{N})$. The likely cause of this effect at low shaker force amplitude is the influence of a slight radial play in the rollingelement bearing of the SFD.

The training data (SFD forces/relative displacements) are prepared for training a chosen neural network architecture using the method in [18].

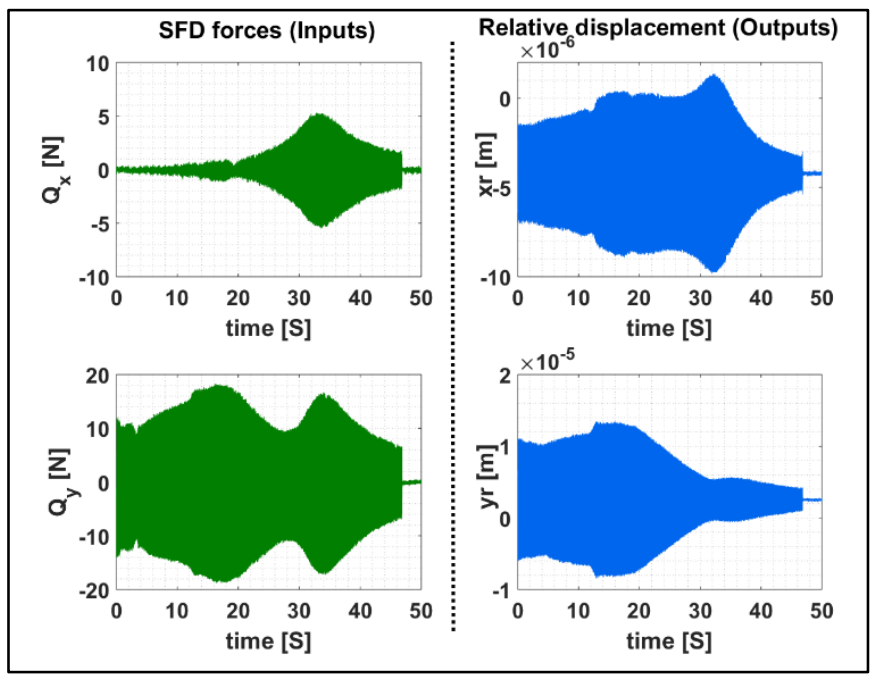

Figure 9: Input/output training data gathered using shakerchirp excitation at $10-100 \mathrm{~Hz}$ and amplitude $20 \mathrm{~N}$ (eq. (1)).

\subsection{INVERSE SFD MODEL IDENTIFICATION USING RNN}

As explained in the Introduction, the inverse model is basically different from the forward model of the SFD in that the forward model is memoryless, which means that the instantaneous SFD forces (output) $\mathbf{f}_{\mathbf{v}}=\left[\begin{array}{ll}Q_{x} & Q_{y}\end{array}\right]^{\mathrm{T}}$ can be obtained from given instantaneous displacements and velocities of the journal relative to the housing, $\mathbf{v}=\left[\begin{array}{ll}x_{\mathrm{r}} & y_{\mathrm{r}}\end{array}\right]^{\mathrm{T}}$, $\dot{\mathbf{v}}=\left[\begin{array}{ll}\dot{x}_{\mathrm{r}} & \dot{y}_{\mathrm{r}}\end{array}\right]^{\mathrm{T}}$ :

$$
\mathbf{f}_{\mathbf{v}}=\mathbf{f}_{\mathbf{v}}(\mathbf{v}, \dot{\mathbf{v}})
$$

where $\mathbf{f}_{\mathbf{v}}$ is a nonlinear function of $\mathbf{v}, \dot{\mathbf{v}}$. On the other hand, with the inverse SFD model, the determination of the instantaneous (current) relative displacement (output) requires the time histories of $\mathbf{f}_{\mathbf{v}}$ and $\mathbf{v}$, as per the Nonlinear Autoregressive Exogenous (NARX) identification method used in time-series modelling [22].

Figures 10 and 11 show the RNN, which is an implementation of the NARX scheme. The external input of the RNN is the signal $\mathbf{f}_{\mathbf{v}}\left(t_{k}\right)$, where $t_{k}=(k-1) \Delta$ denotes discrete times, whilst $k=1,2, \ldots, \Delta$ is the sampling time resolution. The input data is normalised for the network within a range of $[-1,1]$, where $\overbrace{(\tau)}$, refers to the network-normalised version of the variables $(\quad)$ [22].

The output $\breve{\mathbf{v}}\left(t_{k}\right)$ of the RNN is an estimation of $\mathbf{v}\left(t_{k}\right)$, and its normalised form $\tilde{\mathbf{v}}\left(t_{k}\right)$ is internally fed back to the network. Hence, the system memory is taken into account since the RNN includes multiple delays of the signals in the Tapped Delay Lines (TDLs) as in Figure 10. This means that 
the net has internal feedback and is dynamic. TDL no.1 in Figure 11 is a multi-channel line carrying the delayed signals $\widetilde{\tilde{f}_{\mathbf{v}}}\left(t_{k-1}\right), \quad \widetilde{\mathbf{f}_{\mathbf{v}}}\left(t_{k-2}\right), \quad \ldots . \quad \widetilde{\mathbf{f}_{\mathbf{v}}}\left(t_{k-n_{1}}\right) \quad$ in the respective $n_{1}$ channels, whilst TDL no. 2 carries the delayed signals $\quad \tilde{\mathbf{v}}\left(t_{k-1}\right), \quad \tilde{\overrightarrow{\mathbf{v}}}\left(t_{k-2}\right)$, $\widetilde{\mathbf{v}}\left(t_{k-n_{1}}\right)$ in the respective $n_{2}$ channels.

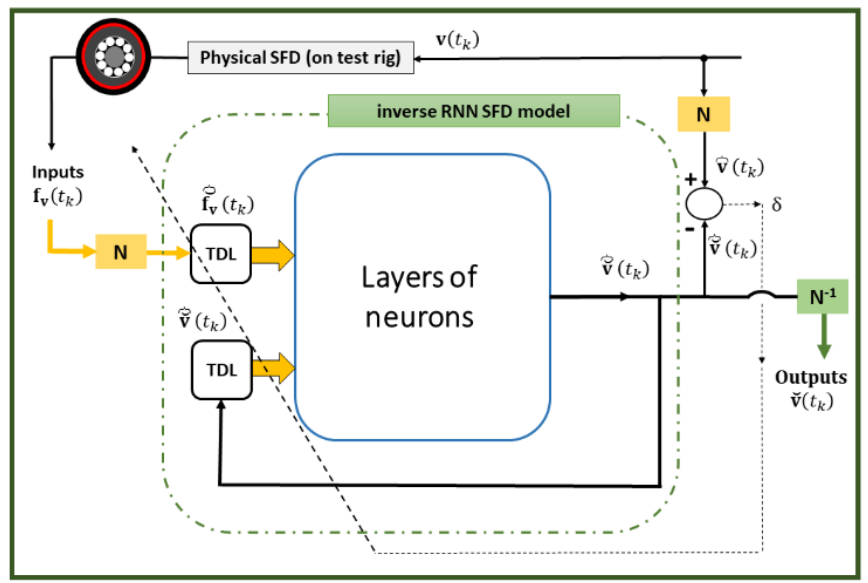

Figure 10: Identification procedure of the RNN inverse SFD model (N: network normalisation; $\mathrm{N}^{-1}$ : de-normalisation; TDL: tapped delay line) [18].

\subsubsection{NETWORK DETAILS}

The RNN structure enclosed within the dashed box in Figure 10 is shown in more detail in Figure 11, which shows the generic architecture and the optimization approach to obtain an RNN inverse model. In total 32,731 pairs of training data were employed to train the RNN and the three sets of empirical data (explained in 3.1) were applied separately to the generic architecture, as shown in Figure 10.

Each of these sets of input/output data were structured randomly into three sub-sets: $60 \%$ for training, $20 \%$ for testing, and $20 \%$ for validation, as shown in Figure 11. These subsets were employed by the Neural Network Toolbox [22] to reach an optimal topology. The number of neurons in the $j^{\text {th }}$ layer is denoted by $S^{(j)}$, where $J$ denotes the total number of layers, and $n_{1}, n_{2}$ respectively denote the number of delays in
TDL no. 1 and TDL no.2. If $\mathbf{a}_{k}^{(j)}$ is the $S^{(j)} \times 1$ vector including the signal outputs of the $j^{\text {th }}$ layer, then ([13]):

$$
\begin{aligned}
& \mathbf{a}_{k}^{(J)}=\tilde{\widetilde{\mathbf{v}}}\left(t_{k}\right) \\
& \mathbf{a}_{k}^{(1)}=\mathbf{g}^{(1)}\left(\mathbf{W}^{(1)} \mathbf{p}_{k}+\mathbf{b}^{(1)}\right) \\
& \mathbf{a}_{k}^{(j)}=\mathbf{g}^{(j)}\left(\mathbf{W}^{(j)} \mathbf{a}_{k}^{(j-1)}+\mathbf{b}^{(j)}\right), j=2, \ldots . J
\end{aligned}
$$

where $\mathbf{p}_{k}$ is a $\left(2 n_{1}+2 n_{2}\right) \times 1$ column matrix containing the inputs of signal to layer no. 1 :

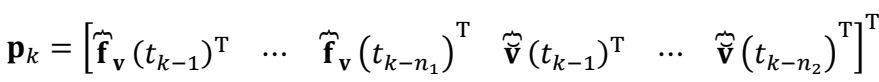

$$
\begin{aligned}
& \widetilde{\mathbf{f}}_{\mathbf{v}}\left(t_{k-n}\right), \tilde{\overrightarrow{\mathbf{v}}}\left(t_{k-n}\right)=\mathbf{0}, \quad t_{k-n}<t_{1}
\end{aligned}
$$

where $\mathbf{W}^{(j)}$ is the matrix of weights, $\mathbf{b}^{(j)}$ is the vector of biases of the $j^{\text {th }}$ layer and $\mathbf{g}^{(j)}()$ is a vector operator comprising the transfer functions of the neurons of the $j^{\text {th }}$ layer.

The identification and training procedures are shown in Figure 10, and Figure 11 shows the parameters of the proposed RNN architecture. These parameters are optimised to reduce the error-difference $\delta$ between the actual data (i.e. target) output $\widetilde{\mathbf{v}}\left(t_{k}\right)$ and the network's output $\tilde{\mathbf{v}}\left(t_{k}\right)$. The architecture of the RNN (Figure 11) uses three layers with different numbers of neurons. There are $n_{1}=2$ delays in the input channel and $n_{2}=2$ delays in the feedback channel. The output channel contains two signals $\left(x_{\mathrm{r}}, y_{\mathrm{r}}\right)$, and so the number of neurons of the final (output) layer is fixed at two.

The tan-sigmoid transfer functions $[13,18,22]$ are used for the neurons, except for the output layer where linear transfer functions are utilised. The Levenberg-Marquardt algorithm (optimisation method) [22] was used in the training to optimise the weights and biases of the RNN (eqs. (5a,b)). Referring to Figure 10, the optimisation objective was the convergence of the mean square error (MSE) to a value below a set tolerance specification.

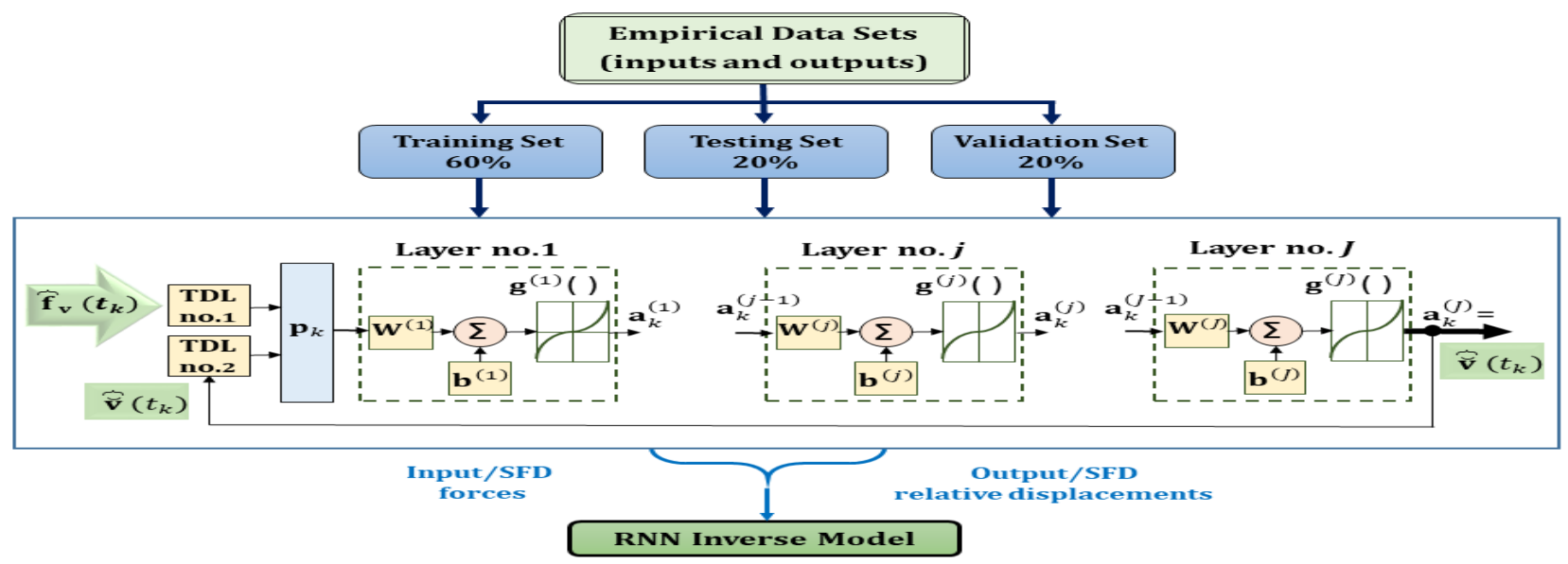

Figure 11: RNN architecture and optimization of its parameters. 
With reference to Figure 11, the best numbers of neurons in layers 1 and 2 ("hidden layers") were obtained using an exhaustive search method that was recently employed in $[18,19]$. With this approach, the number of neurons in each hidden layer was progressively increased and, for each trial architecture, the RNN was trained 10 times. Due to the random initialization of the weights and biases, training multiple times for a given trial architecture was considered necessary to avoid the MSE being trapped in local minima $[18,19]$. For the training data in Figure 9 (measured at shaker force amplitudes of $20 \mathrm{~N}$ ), the architecture of the optimal topology (which gave the lowest MSE) comprised 9, 4, 2 neurons for the three layers respectively.

\section{VALIDATION TESTS: PERFORMANCE RESULTS AND DISCUSSION}

The first step of the post-training validation tests was to generate a vibration SFD response to seeded rotational unbalance excitation using the illustrated rotating rig in Figures 2 and 3. A total of 24 experimental validation data sets were measured by applying four different unbalance masses located at six different angular positions, as per Table 1. These validation sets were then used to test the performance accuracy of the trained networks (i.e. inverse SFD models), which were trained from completely different experimental data (measured in the non-rotating setup, as per section 3). The validation data sets used in this section should not be confused with the validation data (in section 3/Figure 11) employed during the supervised training process.

The trained RNNs were tested to predict the time histories of the journal displacements, $x_{\mathrm{r}}, y_{\mathrm{r}}$, with the inputs to the network being the time histories of the SFD forces, $Q_{x, y}$, which were computed from eqs. $(2 \mathrm{a}, \mathrm{b})$ from the bearing housing vibration induced by the rotational unbalance via the SFD, which provides a nonlinear interface between the rotor and the bearing housing (Figure 3). The predicted outputs of the network were then compared with the time histories of the actual measurements for $x_{\mathrm{r}}(t), y_{\mathrm{r}}(t)$. Figures 12-27 illustrate the measured and predicted relative displacement response signals, $x_{\mathrm{r}}(t), y_{\mathrm{r}}(t)$, together with their frequency spectra, for a variety of unbalance levels ranging from high to low.

Table 1: Seeded unbalance distribution.

\begin{tabular}{|c|c|c|c|c|c|c|}
\hline $\begin{array}{c}\text { unbalance } \\
\text { (gram) }\end{array}$ & \multicolumn{6}{|c|}{$\begin{array}{c}\text { angular location } \\
\left({ }^{\circ}\right)\end{array}$} \\
\hline 12 & \multirow{4}{*}{30} & \multirow{4}{*}{60} & \multirow{4}{*}{120} & \multirow{4}{*}{195} & \multirow{4}{*}{270} & \multirow{4}{*}{330} \\
\hline 10 & & & & & & \\
\hline 9 & & & & & & \\
\hline 6.1 & & & & & & \\
\hline
\end{tabular}

Figures 12 and 13 display the validation tests for the rotational unbalance of $12 \mathrm{~g}$ located at $330^{\circ}$ degrees at rotor speeds of 6,000rpm and 3,500rpm respectively. The time histories of the SFD forces (inputs) are shown in the first column, the outputs of the network are presented in the second column in comparison with the actual measurements. Also, the third column of the Figure 12 shows the steady state trajectory (orbit) plots of the SFD journal relative to the bearing housing, i.e. $y_{\mathrm{r}}$ vs $x_{\mathrm{r}}$.
It should be noted that the clearance boundary of the SFD is nominally a circle of radius $0.09 \mathrm{~mm}$, but measurement showed that it actually has a distorted triangular form as a result of machining irregularity of both the housing bore and journal (as previously reported). This clearance profile was the measured trajectory $\left(y_{\mathrm{r}}\right.$ vs $\left.x_{\mathrm{r}}\right)$ obtained by gently brushing the journal against the housing bore without oil pumped in the clearance when imposing shaker forces of suitably high amplitude and very low frequency [18].

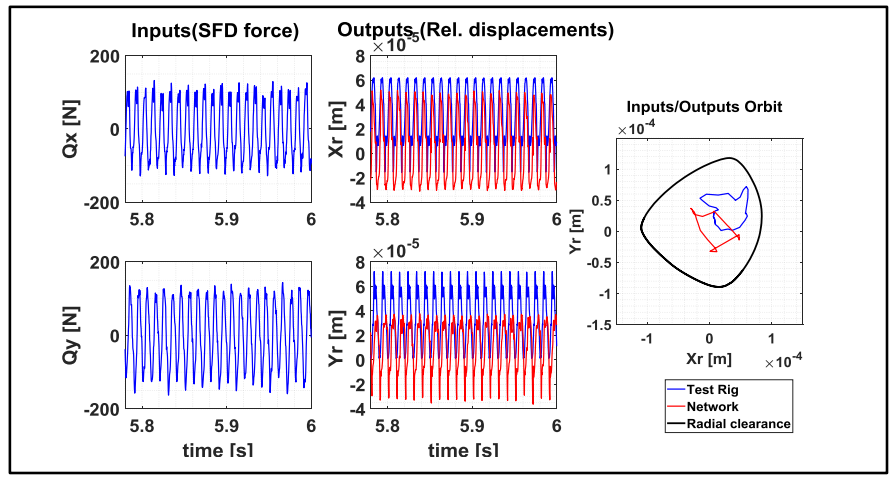

Figure 12: Test for the validation of network inputs/outputs under rotational unbalance excitation conditions at mass/speed $12 \mathrm{~g} / 6,000 \mathrm{rpm}$ at position $330^{\circ}$ : inputs (SFD forces), outputs (relative displacements time histories \& orbits).

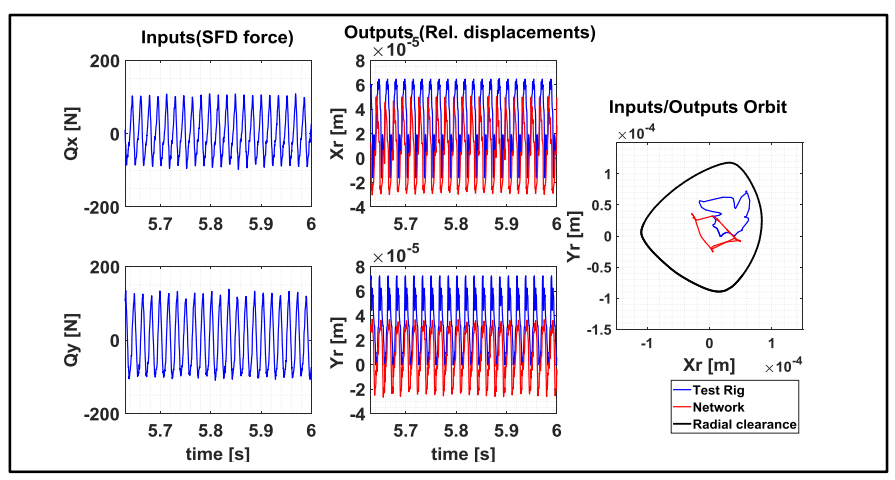

Figure 13: Test for the validation of network inputs/outputs under rotational unbalance excitation conditions at mass/speed $12 \mathrm{~g} / 3,500 \mathrm{rpm}$ at position $330^{\circ}$ : inputs (SFD forces), outputs (relative displacements time histories \& orbits).

The measured and predicted SFD vibrations clearly show highly nonlinear features, unlike those presented in the authors' previous work [18]. In [18], where the vibration was induced by orthogonally-phased perpendicular shakers applied to a non-rotating rotor, the measured orbits were practically elliptical. In the present case, the measured orbits are considerably distorted. The RNN-predicted orbits are similarly distorted. The RNN-predicted peak-to-peak amplitudes in the $x$ and $y$ directions are comparable to the measurement, but there is a discrepancy in the mean values. However, as stated and shown in [9], this discrepancy is not important when using the RNN inverse SFD model to solve the inverse problem for the unbalance, since only the dynamic part of the journal vibration is required. 
The observed nonlinearities in Figures 12, 13 are consistent with the fact that the amplitudes of the SFD force time histories under these conditions are considerably higher than those obtained in the generation of the training data using shakers (Figure 9).

The frequency spectra (from the Fast Fourier Transform (FFT)) in Figures 14, 15 show that the RNN-predicted time histories accurately track the major (synchronous) frequency of the measured response. Moreover, the frequency spectra of the RNN-predicted time histories also manage to predict some of the non-synchronous frequencies (including the second harmonic), as indicated by the arrows.

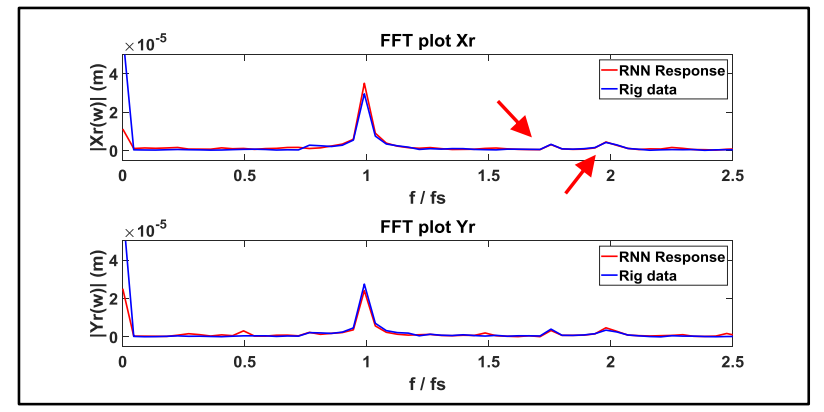

Figure 14: FFT comparison of the measured with predicted relative displacements $\left(x_{\mathrm{r}}, y_{\mathrm{r}}\right)$ under rotational unbalance excitation conditions at mass/speed of $12 \mathrm{~g} / 6,000 \mathrm{rpm}$ at position $330^{\circ}$.

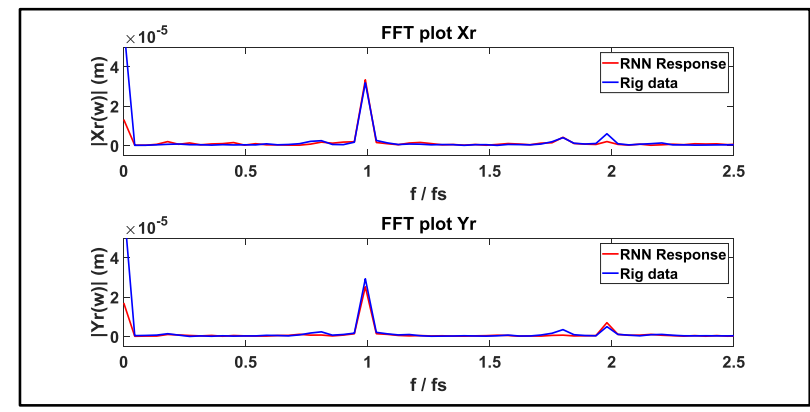

Figure 15: FFT comparison of the measured with predicted relative displacements $\left(x_{\mathrm{r}}, y_{\mathrm{r}}\right)$ under rotational unbalance excitation conditions at mass/speed of $12 \mathrm{~g} / 3,500 \mathrm{rpm}$ at position $330^{\circ}$.

A broadly similar degree of correlation is seen for other unbalance levels, Figures 16-27, although the correlation appears to deteriorate with decreasing unbalance. Also, in some cases, the frequency spectra of the RNN-predicted time histories show faint non-synchronous frequency components that were not observed in the measurement. Nonetheless, the RNN predictions correctly track the synchronous frequency of the nonlinear response, which is the feature that is needed for the solution of the inverse problem for unbalance identification $[9,13]$.

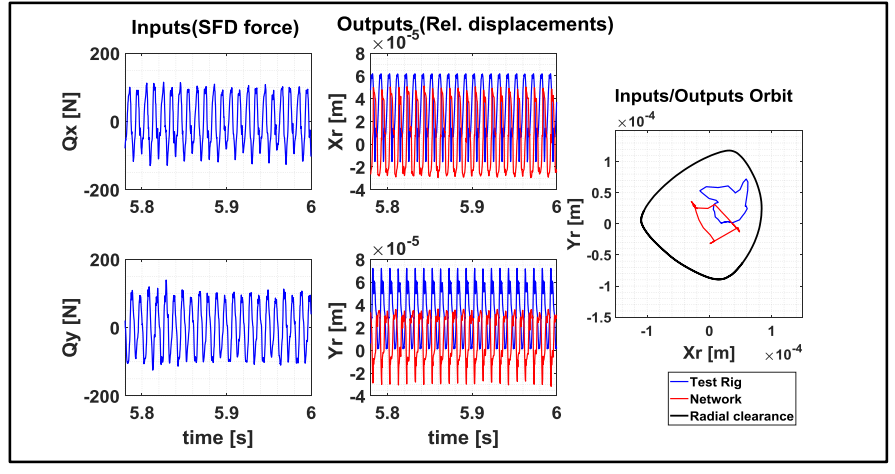

Figure 16: Test for the validation of network inputs/outputs under rotational unbalance excitation conditions at mass/speed $10 \mathrm{~g} / 6,000 \mathrm{rpm}$ at position $195^{\circ}$ : inputs (SFD forces), outputs (relative displacements time histories $\&$ orbits).

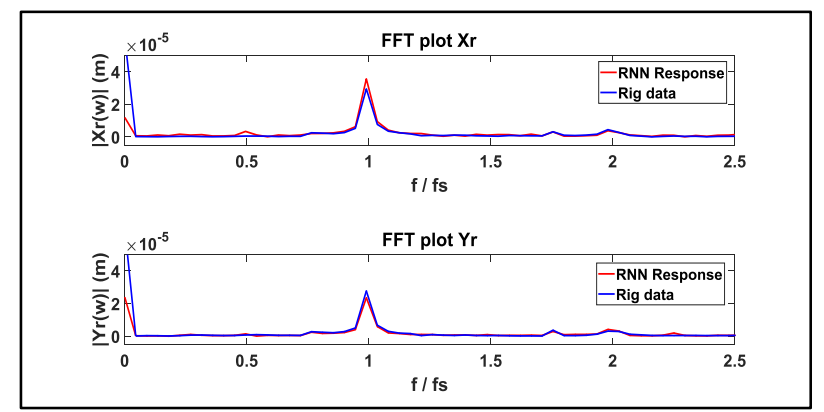

Figure 17: FFT comparison of the measured with predicted relative displacements $\left(x_{\mathrm{r}}, y_{\mathrm{r}}\right)$ under rotational unbalance excitation conditions at mass/speed of $10 \mathrm{~g} / 6,000 \mathrm{rpm}$ at position $195^{\circ}$.

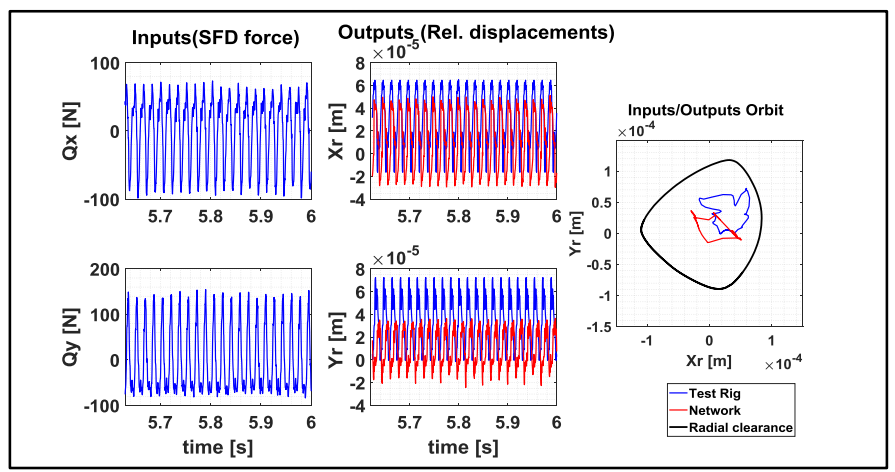

Figure 18: Test for the validation of network inputs/outputs under rotational unbalance excitation conditions at mass/speed $10 \mathrm{~g} / 3,500 \mathrm{rpm}$ at position $195^{\circ}$ : inputs (SFD forces), outputs (relative displacements time histories \& orbits). 


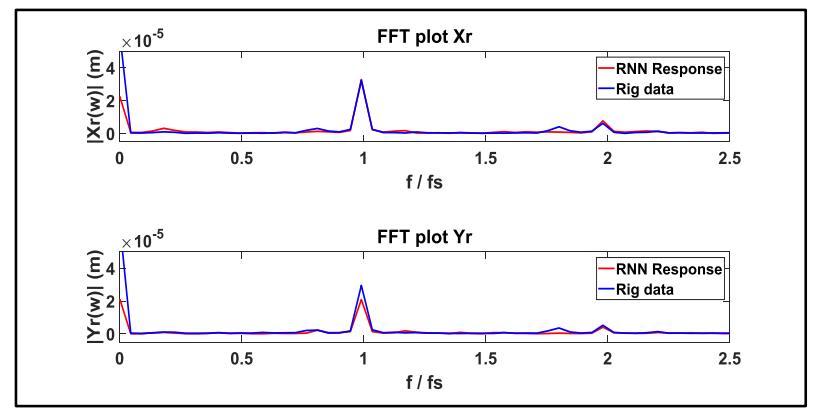

Figure 19: FFT comparison of the measured with predicted relative displacements $\left(x_{\mathrm{r}}, y_{\mathrm{r}}\right)$ under rotational unbalance excitation conditions at mass/speed of $10 \mathrm{~g} / 3,500 \mathrm{rpm}$ at position $195^{\circ}$.

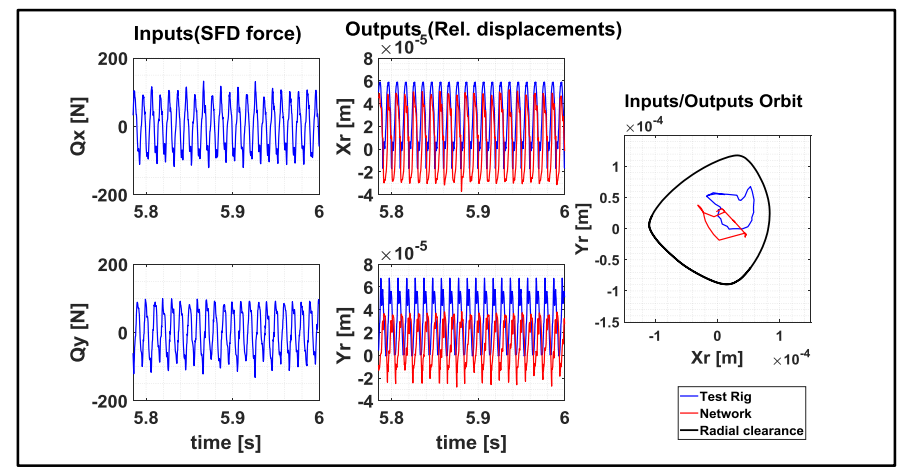

Figure 20: Test for the validation of network inputs/outputs under rotational unbalance excitation conditions at mass/speed $9 \mathrm{~g} / 6,000 \mathrm{rpm}$ at position $120^{\circ}$ : inputs (SFD forces), outputs (relative displacements time histories $\&$ orbits).

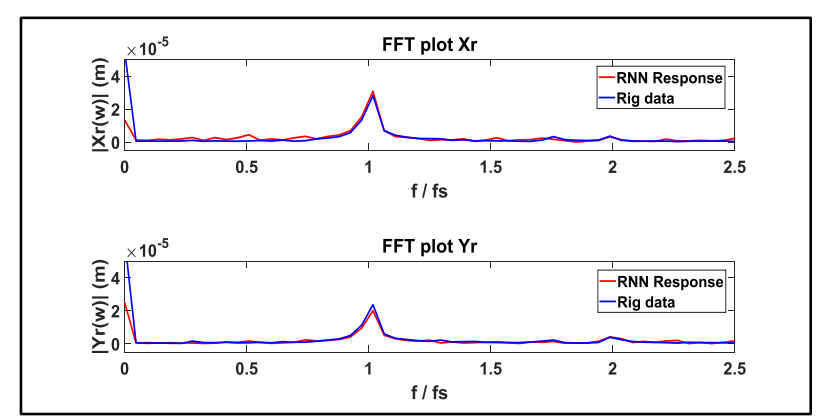

Figure 21: FFT comparison of the measured with predicted relative displacements $\left(x_{\mathrm{r}}, y_{\mathrm{r}}\right)$ under rotational unbalance excitation conditions at mass/speed of $9 \mathrm{~g} / 6,000 \mathrm{rpm}$ at position $120^{0}$.

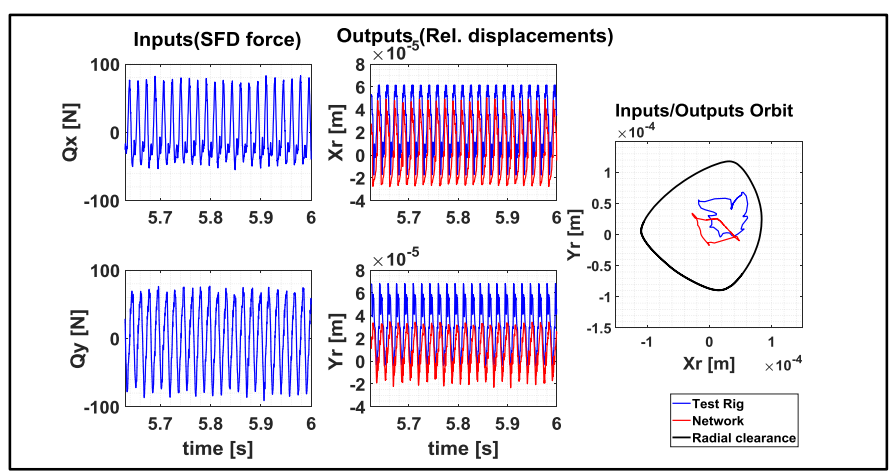

Figure 22: Test for the validation of network inputs/outputs under rotational unbalance excitation conditions at mass/speed $9 \mathrm{~g} / 3,500 \mathrm{rpm}$ at position $120^{\circ}$ : inputs (SFD forces), outputs (relative displacements time histories \& orbits).

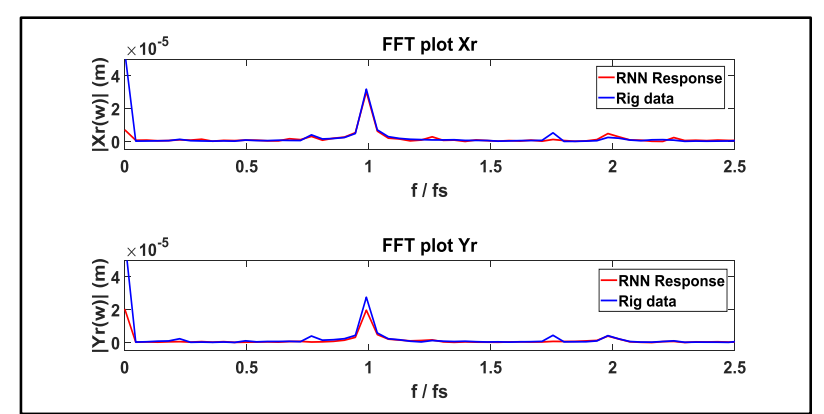

Figure 23: FFT comparison of the measured with predicted relative displacements $\left(x_{\mathrm{r}}, y_{\mathrm{r}}\right)$ under rotational unbalance excitation conditions at mass/speed of $9 \mathrm{~g} / 3,500 \mathrm{rpm}$ at position $120^{\circ}$.

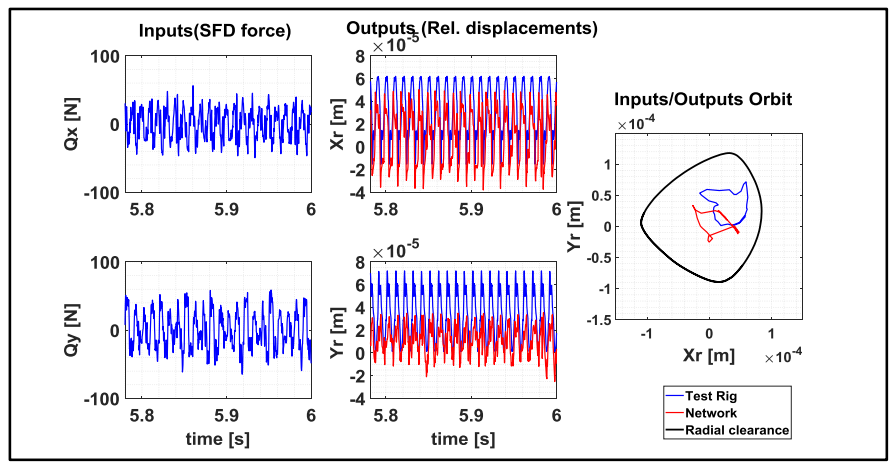

Figure 24: Test for the validation of network inputs/outputs under rotational unbalance excitation conditions at mass/speed $6.1 \mathrm{~g} / 6,000 \mathrm{rpm}$ at position $30^{\circ}$ : inputs (SFD forces), outputs (relative displacements time histories \& orbits). 


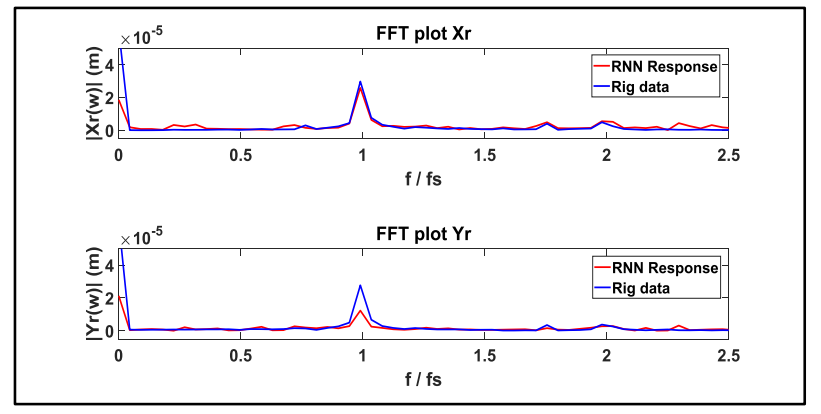

Figure 25: FFT comparison of the measured with predicted relative displacements $\left(x_{\mathrm{r}}, y_{\mathrm{r}}\right)$ under rotational unbalance excitation conditions at mass/speed of $6.1 \mathrm{~g} / 6,000 \mathrm{rpm}$ at position $30^{\circ}$.

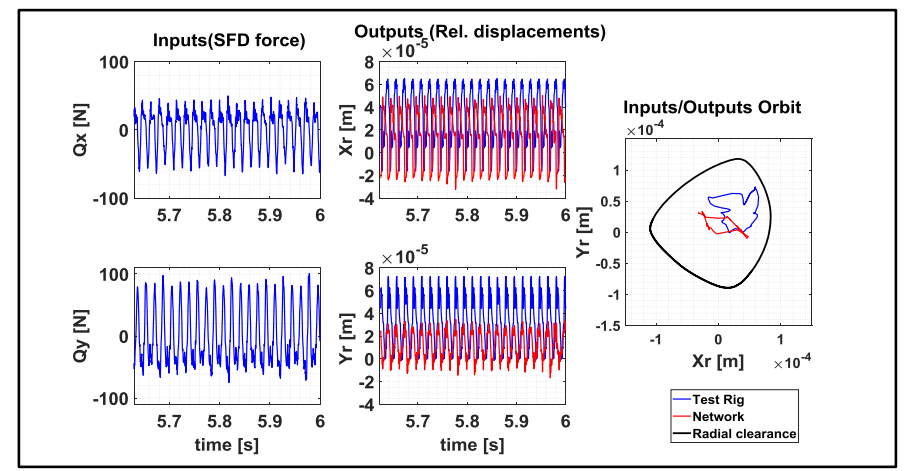

Figure 26: Test for the validation of network inputs/outputs under rotational unbalance excitation conditions at mass/speed $6.1 \mathrm{~g} / 3,500 \mathrm{rpm}$ at position $30^{\circ}$ : inputs (SFD forces), outputs (relative displacements time histories $\&$ orbits).

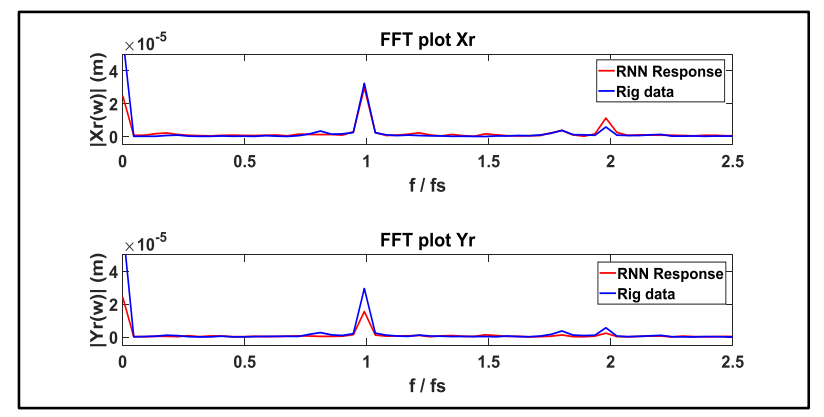

Figure 27: FFT comparison of the measured with predicted relative displacements $\left(x_{\mathrm{r}}, y_{\mathrm{r}}\right)$ under rotational unbalance excitation conditions at mass/speed of $6.1 \mathrm{~g} / 3,500 \mathrm{rpm}$ at position $30^{\circ}$.

\section{CONCLUSIONS}

In this paper, for the first time, a RNN of an inverse bearing model that was identified from experimental data generated under simulated rotational conditions was validated under actual rotational (i.e. unbalance-driven) vibration conditions. The necessary modifications to the test rig were presented, together with the identification/training procedure. The chirp excitation used in the training methodology provided, with less training effort, RNNs that can offer satisfactory predictions for the SFD bearing's nonlinear response. The frequency spectra of the time histories output from the RNN were shown to correctly track the synchronous frequency of the actual unbalance-driven response, despite the evident nonlinearity of the orbital motion. This is an important test, because the Fourier coefficients of the SFD relative displacements are strongly dependent on the fundamental frequency and these Fourier coefficients are essential for the solution of inverse rotor-bearing problem. Furthermore, non-synchronous/second harmonic components observed in the frequency spectra of the actual response were predicted, although extra faint frequencies were also predicted in some cases. In a forthcoming paper, the inverse SFD model of this paper shall be used within the solution process of the unbalance identification inverse problem.

\section{NOMENCLATURE}

A

$\mathbf{a}_{k}^{(j)} \quad$ vector of the signal outputs of the $j$ th

neural network layer, Sec. 3

b neural network bias vector, Sec. 3

$\mathrm{f}_{\text {init }} \quad$ initial shaker excitation frequency $(\mathrm{Hz})$

$\mathrm{f}_{\text {end }} \quad$ finial shaker excitation frequency $(\mathrm{Hz})$

$\mathbf{f}_{\mathbf{v}} \quad$ SFD force vector

$\mathbf{g}^{(j)} \quad$ vector of neural network activation

functions for layer no. $j$, Sec. 3

$j \quad$ layer number of the network, Sec. 3

$J \quad$ total number of layers within the network, Sec. 3

$M_{\mathrm{H} x}, \quad$ effective masses of the support structure

$M_{\mathrm{H} y} \quad$ in the $x$ and $y$ directions respectively $(\mathrm{kg})$

$K_{H x}$, stiffness constants of the support

$K_{H y} \quad$ structure in the $x$ and $y$ directions

respectively $(\mathrm{N} / \mathrm{m})$

$\mathrm{N} \quad$ network normalization, Sec. 3

$\mathrm{N}^{-1} \quad$ reverse normalization, Sec.3

the column matrix comprising the signal inputs

$\mathbf{p}_{k} \quad$ to layer no. 1 of network. Sec. 3

$P_{x}(t), \quad$ shaker forces simultaneously applied at

$P_{y}(t) \quad$ the collar in $x$ and $y$ directions $(\mathrm{N})$

$Q_{x}, Q_{y} \quad$ squeeze-film damper forces in $x$ and $y$

directions $(\mathrm{N})$

$S^{(j)} \quad$ number of neurons in the layer $j^{\text {th }}$, Sec. 3

$t \quad$ time (s)

$t_{k} \quad$ discrete time (s)

$=\left[\begin{array}{ll}x_{\mathrm{r}} & y_{\mathrm{r}}\end{array}\right]^{\mathrm{T}}$ i.e. vector of the

$\mathbf{v} \quad$ instantaneous Cartesian displacements of journal relative to housing $=\left[\begin{array}{ll}\dot{x}_{\mathrm{r}} & \dot{y}_{\mathrm{r}}\end{array}\right]^{\mathrm{T}}$ i.e. vector of the $\dot{\mathbf{v}}$ instantaneous Cartesian velocities of the journal relative to the housing

$\tilde{\mathbf{v}}\left(\boldsymbol{t}_{\boldsymbol{k}}\right) \quad$ the output of the network.

$\mathbf{W}^{(j)} \quad$ matrix of network weights at $j$ th layer neural network. Sec. 3

$x, y$ displacements of the SFD journal

$x_{\mathrm{r}}, y_{\mathrm{r}} \quad$ centre relative to bearing housing centre (m) 


$\begin{array}{ll}x_{H}, y_{H} & \begin{array}{l}\text { absolute Cartesian displacements of the } \\ \text { bearing housing }(\mathrm{m}) \\ \text { accelerations of the bearing housing } \\ \ddot{x}_{H}, \ddot{y}_{H}\end{array} \\ \begin{array}{l}\left(\mathrm{m} / \mathrm{s}^{2}\right) \\ \text { error between the network output and } \\ \text { training target. Sec. } 3\end{array} \\ \begin{array}{l}\text { Network prediction for the variable }(\text { ) } \\ \text { Network-normalised version of the } \\ \text { variable }()\end{array}\end{array}$

\section{REFERENCES}

[1] R. Snieder, The role of nonlinearity in inverse problems, Inverse Probl. 14 (1998) 387-404.

[2] P.M. D. Peters, R. Nordmann, B. Domes, Inverse Determination of Imbalance Distributions, in: in: Eighth International Conference on Vibrations in Rotating Machinery 7-9 September 2004, University of Wales, Swansea, UK, IMechE Conference Transactions 2004-2, 521-530., n.d.

[3] V. Dicken, P. Maaß, I. Menz, J. Niebsch, R. Ramlau, Nonlinear inverse unbalance reconstruction in rotor dynamics, Inverse Probl. Sci. Eng. 13 (2005) 507-543.

[4] R. Ramlau, V. Dicken, P. Maaß, C. Streller, A. Rienäcker, Inverse imbalance reconstruction in rotordynamics, ZAMM - J. Appl. Math. Mech. / Zeitschrift Für Angew. Math. Und Mech. 86 (2006) 385-399.

[5] J.C. Gómez-Mancilla, J.A. Meda-Campaña, S.G. TorresCedillo, V.R. Nossov, Model Derivation and Numerical Simulation for a Pivoted Rigid Rotor-Bearing System, Appl. Mech. Mater. 15 (2009) 89-94.

[6] Y. Ishida., T. Yamamoto, Linear and nonlinear rotordynamics: a modern treatment with applications, John Wiley \& Sons, 2013.

[7] S.G.T. Cedillo, P. Bonello, An equivalent unbalance identification method for the balancing of nonlinear squeeze-film damped rotordynamic systems, J. Sound Vib. 360 (2016) 53-73.

[8] S.G.T. Cedillo, P. Bonello, G.G. Al-Ghazal, J.C. Pérez, A.R. Solis, Effectiveness Testing of an Inverse Method for Balancing Nonlinear Rotordynamic Systems, in: Proc. ASME Turbo Expo 2018 Turbomach. Tech. Conf. Expo., 2018.

[9] S.G.T. Cedillo, G.G. Al-Ghazal, P. Bonello, J. Cortés Pérez, Improved non-invasive inverse problem method for the balancing of nonlinear squeeze-film damped rotordynamic systems, Mech. Syst. Signal Process. 117 (2018) 569-593.

[10] Z. Chen, Y. Jiao, S. Xia, W. Huang, Z. Zhang, An efficient calculation method of nonlinear fluid film forces in journal bearing, Tribol. Trans. 45 (2002) 324-329.

[11] F.A. Rodrigues, F. Thouverez, C. Gibert, L. Jezequel, Chebyshev polynomials fits for efficient analysis of finite length squeeze film damped rotors, J. Eng. Gas Turbines Power. 125 (2003) 175-183.

[12] K.H. Groves, P. Bonello, Empirical identification of squeeze-film damper bearings using neural networks, Mech. Syst. Signal Process. 35 (2013) 307-323.

[13] S.G. Torres Cedillo, P. Bonello, Empirical identification of the inverse model of a squeeze-film damper bearing using neural networks and its application to a nonlinear inverse problem, J. Vib. Control. (2016).

[14] A.W. Lees, M.I. Friswell, the Evaluation of Rotor Imbalance in Flexibly Mounted Machines, J. Sound Vib. 208 (1997) 671-683.

[15] J.K. Sinha, A.W. Lees, M.I. Friswell, Estimating unbalance and misalignment of a flexible rotating machine from a single run-down, J. Sound Vib. 272 (2004) 967-989.

[16] J.K. Sinha, M.I. Friswell, A.W. Lees, the Identification of the Unbalance and the Foundation Model of a Flexible Rotating Machine From a Single Run-Down, Mech. Syst. Signal Process. 16 (2002) 255-271.

[17] A.W. Lees, J.K. Sinha, M.I. Friswell, Model based identification of rotating machines, Mech. Syst. Signal Process. 23 (2009) 1884-1893.

[18] G.G. Al-Ghazal, P. Bonello, \& S.G. Torres Cedillo, Improved Empirical Identification of the Inverse Model of a Squeeze-Film Damper Bearing based on a Recurrent Neural Network, in: Proc. ASME Turbo Expo 2018 Turbomach. Tech. Conf. Expo., 2018.

[19] B.R. Al-Kaseem, H.S. Al-Raweshidy, A.-D. Yousif, K. Banitsas, A New Intelligent Approach for Optimising 6LoWPAN MAC Layer Parameters, IEEE Access. (2017) 1-1.

[20] P. Bonello, The Non-Linear Modelling Of Squeeze Film Damped Rotor-Dynamic Systems: An Efficient Integrated Approach, University Of Southampton Faculty of Engineering and Applied Science Institute Of Sound and Vibration Research, 2002.

[21] Abaqus, User's Manual, Version 6.14. Dassault Systémes Simulia Corp, Providence, Rhode, 2014.

[22] M.H. Beale, M.T. B.Hagan, H.B. and Demuth, Neural Network Toolbox ${ }^{\mathrm{TM}}$ User's Guide R2017a, The MathWorks, Inc., n.d. 